\title{
F-LARSP 1.0: An Adaptation of the LARSP Language Profile for French.
}

\author{
Christelle Maillart $^{1} \quad$ Christophe Parisse ${ }^{2} \quad$ Jodi Tommerdahl $^{3}$
}

1 University of Liège, Belgium

2 MoDyCo, INSERM, CNRS-Université Paris Ouest Nanterre la Défense

3 University of Texas at Arlington

\section{Abstract}

The LARSP (Language Assessment, Remediation and Screening Procedure) (Crystal et al., 1976) is a linguistic profile commonly used by researchers and clinicians to carry out detailed analyses of the grammar and morphology of children's spontaneous language samples. This paper discusses the methods used to adapt the profile from English to French using a large corpus of child language in order to accurately assign morphosyntactic structures to age-based stages.

Keywords: LARSP; morphosyntax; language acquisition; SLI; French

\section{FOR REVISION AND RESUBMISSION}

\section{Introduction}

The LARSP (Language Assessment, Remediation and Screening Procedure) (Crystal et al., 1976) is a linguistic profile commonly used by researchers and clinicians to carry out a "comprehensive and consistent linguistic analysis" (Ball, 1999); more specifically a detailed guide for analysis of the grammar and morphology of English-speaking children's spontaneous language samples. The profile was developed in a manner that allows the user to clearly see the child's grammatical strengths and weaknesses in relation to their chronological age. This is made possible by the notion that the order in which syntactic structures are acquired is relatively stable, at least until the age of about 5 (Brown, 1973). Correlation of a child's morphosyntactic production to their age provides the therapist with vital information regarding an array of areas including the possible presence of language impairment (Gavin et al. 1993), appropriate remediation planning (McCartney 1993, p. 226), and a tool for measuring treatment efficacy (Joffe, Doyle and Penn, 1996). The profile is therefore especially useful for children who are suspected of or who have been diagnosed with having forms of language difficulties such as 
Specific Language Impairment (SLI) where morphology and syntax are commonly affected (Oetting \& Hadley, 2009).

French-speaking speech-therapists don't frequently use spontaneous language to assess the morphosyntactic level of their young patients. Two main explanations could be proposed for the reason behind this: 1) the absence of developmental norms to describe different levels of morphosyntactic acquisition; 2) the lack of validated analysis tools in French. In other words, French clinicians may well be aware of the potential weaknesses of using spontaneous samples in clinical decisions. Francophone clinicians are therefore reliant on standardized assessment tools.

It would therefore be useful to create a tool which would show developmental norms, provide a clear linguistic analysis, and that is also easy to use. Three major tools that could fulfill these requirement have been developed, mainly for English, for the purpose of evaluating grammatical development in natural language production: LARSP (Crystal et al., 1976), IPSyn (Scarborough, 1990), and DSS (Lee, 1974). All three have strengths and weaknesses. The DSS is interesting in that it provides simple grammatical information that is easy to compute, but today, with the help of computer analysis (see below), it has become easier to compute complex information. In deciding between the LARSP and the DSS, we have chosen to use the tool providing the most detailed linguistic information in order to obtain the most precision and widest options regarding analysis. The strength of the LARSP when compared to the IPSyn was that the LARSP is organised in age-related stages, which is helpful for language evaluation. Overall, the LARSP appeared to have the most potential, but only if its computation could become automatised and accurate developmental norms for French-speaking children could be established.

The project was therefore approached with the following aims:

(1) to provide French speaking clinicians with the most useful version of the LARSP possible

This primary goal can be broken down into five sub-goals:

(a) to omit all LARSP structures from the original English chart that do not exist in French and to add structures specific to French

(b) to simplify the use of the tool through the development of a computerised system that can assign F-LARSP 1.0 categories to a language transcript

(c) to verify the accuracy of that computerised system

(d) to use the computerised system to link potential F-LARSP 1.0 structures to chronological age ranged which are accurate and based on a large corpus of child language

(e) to finalise the placement of elements on the chart based on criteria similar to that used on 
the Dutch LARSP adaptation (Bol and Kuiken 1990) and the elements' ability to be identified by the computer programme

A secondary goal of producing the F-LARSP 1.0 was to encourage researchers working in different languages to adapt the LARSP to further languages by providing a clear outline of how this process might take place.

\section{Description of the LARSP chart in English}

Carrying out a full LARSP consists of seven consecutive steps including (i) sampling, (ii) transcription, (iii) grammatical analysis, (iv) structure count, (v) pattern evaluation, (vi) statement of remedial goals, and (vii) statement of remedial procedures (Crystal et al. 1976). The authors suggest collecting a sample for approximately 30 minutes split between natural play and discussion of experiences outside of the immediate surroundings in order to record at least 50 utterances.

Areas at the top of the chart exist for recording information such as stimulus and response types, major and minor sentences, and problematic productions. The main body of the LARSP is described by its authors as having seven stages, each relating to a chronological age between 0;9 and 4;6+. The stages are linked to ages based on Brown's seminal work (1973) although the authors suggest that the ages be taken with caution (Crystal et al. 1976).

Generally, stages I to IV correspond to the same number of either clause or phrase elements being used together. For example, at clause level III, we would mark an example of the child using the three-part SVO structure. Similarly, a single word utterance might be labeled as a noun or verb and marked at stage I.

Stage V represents the level of coordination and subordination while stages VI and VII look at errors, discourse structure and style.

A column labeled 'word' is also present on the chart which lists morphological inflections in their acquired order. The list is also based on Brown's work (1973) and the structures are said to be developed throughout stages II to IV. Each time a child uses a particular structure in a language sample, a tick is made by the name of the corresponding structure on the chart.

The completed chart is then available to the researcher or clinician to compare to patterns described in the LARSP's instructions and to plan any required remediation procedures.

\section{Adaptation of LARSP to other languages}

The utility of the LARSP, originally designed for Anglophone use, has led to its adaptation to several other languages. Those which have been published for an international audience include Welsh (Ball 1988), Dutch (Bol and Kuiken 1990), Irish (Hickey 1990) and Persian (Samadi and Perkins 1998). Out of these four, only the Dutch version includes the guidelines of 
chronological age. This is due to the lack of information about normal syntactic development and/or the small sample size used in the adaptations of the three other versions. The Dutch version thereby presents a more useful LARSP chart presenting clear evidence-based criteria used to determine whether a given structure should be included on the chart, and if so, at which stage in the chart:

a. the structure should be used by at least $50 \%$ of the population at one particular Stage;

b. the median of the frequency with which a structure is used should have a value of at least 1.0 .

Each of the adaptations of the foreign language LARSPs takes into consideration the specific nature of the target language's morphosyntactic structure and omits, adapts and adds items in order to suit this nature. The Irish and Persian and Welsh LARSP have a similar arrangement on the page to the English LARSP as both keep the upper boxes of the categories Unanalysed/Problematic, Responses, Spontaneous and Reaction and list approximately the same number of structures on the overall chart. The Welsh version also expands upon the original LARSP by developing a separate chart for morphology and a third for word-initial consonant mutations which although phonological, are triggered by conditions of syntax and morphology. In contrast to this, the Dutch version does away with most of these boxes and also greatly slims the number of structures. This slimming down is an attempt to limit the structures used to those that "play a relevant role in the language development of pre-schoolers" and which are also used regularly.

\section{Description of French Morphosyntax}

At the earliest stages of adapting the LARSP to another language, the researcher must consider the structure of the English language for which the original LARSP was designed and in turn compare that structure with that of the new target language. Although each language will have idiosyncrasies which may be useful to place on the LARSP, two major areas are at the heart of the LARSP and must be carefully considered for all adaptations. These are the order and composition of clause elements (subject, verb, object, complement and adverbial) and details of a language's morphological elements. Information about French morphosyntax is included in order to provide the framework of ideas that needed to be considered at the beginning of this adaptation.

\section{French word order}

The canonical word order of French, as in English, is SVO (subject - verb - object). There are some exceptions: the use of object clitics leads to SOV structure (e.g. il le mange / he eats it), relative clause tolerate VS order (e.g. VS - l'homme qu'aime Marie / the man that Marie loves but also OSV que Marie aime / that Marie loves) and the interrogative structure allows the VSO order (e.g. connais-tu ce garçon? / do you know this boy?). The canonical SVO order tend to be 
preserved in interrogative forms using a rising intonative pattern (e.g. La fille embrasse le garcon ? / The girl kisses the boy?) or the "est-ce que" locution (e.g. Est-ce que la fille embrasse le garçon ? / Does the girl kiss the boy?). Null subjects are not permitted (* neige / *snows), except for imperatives. This feature lays down use of impersonal subject (e.g. il neige / it snows or it is snowing) (Kail, 1989).

As in English, all determiners are located before the noun: demonstrative, indefinite, interrogative, negative, and possessive (e.g. cette table "this table", une table "a table", quelle table ? "which table ?", aucune table "no table", ma table "my table"). In contrast to typical English usage, adjectives are placed after the noun they modify (e.g. Une table ronde "a round table") with the exception of a small set (e.g. petit "small").

Some items have a syntactic function. They are known as free morphemes. This category is composed of auxiliaries, pronouns, prepositions and determiners. Most of them have a fixed position in the sentence (in the beginning of a prepositional phrase for a preposition, in preverbal position for auxiliaries or clitic pronouns).

\section{French morphology}

French is a moderately inflected language. Due to historical erosion of endings pronunciation, its morphology is characterised by an important homophony in the spoken language which is in turn reflected on the chart. Verbal forms with different inflections are pronounced in a similar way (e.g. je mange, tu manges, il mange, ils mangent). $94 \%$ of the verbal forms, all the first group verbs described above, are homophonous for a number of inflections (e.g. il chante/ ils chantent) (Paradis and El Fenne, 1995). In French, the gender/ number of many nouns/adjectives is made clear only by the determiner. When audible, these inflections are formed by a vocalic (e.g. cheval / chevaux ; boeuf/boeufs) or consonantic (e.g. petit / petite) morpho-phonological alternation (Dubois, 1965). The vocalic alternations are so infrequent that they tend to be lexicalised. The morpho-phonological alternation " consonant/Ø " is more frequently used to mark the number on the verb (e.g. part-partent ; dort - dormant). This alternation is used in many different morphological mechanisms (verbal/nominal/adjectival morphology; derivation, liaison e.g. un petit enfant vs. un petit garçon). Past events are expressed by different tenses depending on several factors. Finished events occurring in the past are expressed by the "passé composé" with the auxiliaries "avoir" (have) or "être" (be) plus the past participle (J'ai mangé puis je suis parti). Interrupted events occurring in the past are expressed by the "imparfait' with the stem of the verb plus the following endings (-ais, -ais, -ait, -ions,- iez, -aient, e.g. je mangeais lorqu'il est arrivé). Upcoming events are expressed by two frequent tenses: "futur simple" for future events and "futur proche" for very close future events. The formation of simple future is the same for the three different groups: the stem of the verb plus the following endings (-rai, -ras, -ra, -rons,- rez, -ront, e.g. je mangerai). The "futur proche" is formed from the addition of the semi-auxiliary « aller » and the infinitive form of the verb (e.g. je vais manger). This is reflected on the chart with the inclusion of the ModInf category (modal + 
infinitive).

The article system contains definite and indefinite forms. Articles precede the noun and agree with it in number and gender. The inflections of gender or number within pronouns and determiner classes are based on a vocalic alternation.

To repeat, the primary aim of this project is to produce a francophone adaptation of the original English LARSP. Further aims include the development of evidence-based age-related stages as well as a computerised system allowing the LARSP to be carried out automatically from a transcribed sample. This paper will now present the sequence of steps followed for the purpose of achieving these aims.

\section{Methods}

A series of six steps was taken in order to achieve the stated aims. Steps I and II were carried out to fulfill goal (a) of identifying appropriate structures for potential placement on the French chart.

Step I of F-LARSP 1.0 design involved evaluating structures present on the English language LARSP in regard to whether each was potentially appropriate for the F-LARSP. The only limitation placed on each target structure was whether the same form existed in the French language. Forms existing in English but not French were identified and omitted from the chart. Examples of this include structures such as the plural forms of nouns which are present in French writing but not audible in speech, the contraction $n$ 't from the Word column, the genitive and the contracted copular.

Step II involved the close analysis of several transcripts of child language in French, noting structures occurring which did not exist in the English version and adding them to a first draft of the F-LARSP. These steps were carried out in joint meetings of the three authors who are all bilingual in French and English, with two being native French speakers. New target structures specific to French were added. Examples of this include structures such as $n \& F E M$ indicating the feminine form of a noun such as la patineuse (the female ice skater), and dislo-G and dislo$D$ which represent dislocations (repetitions of noun phrases by a pronoun) to the left and right such as in the following sentences:

A) Moi je suis contente. (Me, I am happy.)

B) Elle est belle la jeunesse. (It is beautiful, youth.)

The resulting product of steps I and II was a master list of morphosyntactic structures existing in any of the French child-language transcripts which had been identified by hand. 
Step III consisted of software development by the author C. Parisse's that can accurately identify most of the identified morphosyntactic structures in a language sample. Transcriptions of the recordings were grammatically coded for part-of-speech using the software CLAN from the CHILDES project (MacWhinney, 2000). This software is able to produce a part-of-speech syntactic analysis (Parisse and Le Normand, 2000). This analysis was used as a starting point to produce a computerised version of the F-LARSP, using a handmade software tool. While the automatic analysis correctly labeled most French parts of speech and target F-LARSP structures, a small number of features of French, such as dislocations, were impossible to code by machine. Features of level 6 and 7 from the English LARSP as well as some features of level 5 were not able to be recognised by the new program due to their variety and complexity of possible forms and were therefore not coded. Details of the software development and implementation will be made available in Parisse, Maillart and Tommerdahl (in press).

Step IV used the software developed in step III to analyse a large corpus of child language of children ranging in age from 1;6-4;0. The software identified and counted the number of productions of each structure for each transcription in the large corpus, thereby providing data for establishing production norms for each age.

\section{The corpus}

The ability of the F-LARSP 1.0 to accurately link a chronological age to a stage of morphosyntactic productions required a corpus of child language. The corpus used was created by Le Normand (1986; Parisse and Le Normand, 2006). Typically developing participants were recruited from homes and nurseries in Paris, France and its immediately surrounding areas. Participants included 312 typically developing children (142 girls and 170 boys) ranging in age from 24 to 48 months. Selection criteria included normal hearing measured by an auditory screening test, scoring in the normal range on an age-appropriate nonverbal cognitive test (Symbolic Play Test; Lowe and Costello, 1976) and being a native speaker of French.

This transversal corpus contains 316 recordings of 20 minutes each, from the age of 2;0 to $4 ; 0$. For the needs of this project, additional recordings (Vial, 2010 ; Dumez, 2010) were carried out of children aged 18 and 21 months.

The corpus was gathered using the following methods. Each child participated in a dyadic interaction with a familiar adult partner (parent or nursery teacher) either in the child's home, nursery or school. The child and adult were seated at a small table, and the same standardised set of 22 Fisher-Price toys (house, family members, dog, beds, chairs, tables, rocking horse, stroller, cars, staircase) was used with all children. Similar but slightly modified play material was used for the younger children. Materials were more recent and from the brand Playmobil ${ }^{\circ}$ and some elements were changed to avoid choking hazards. Basic information about the corpus' data including the number of children at each age, their average number of utterances in their samples and their MLU is shown in table 1 below. Note that the mean length of utterance (MLU) was calculated according to the number of words per utterance. The MLU measurements of the 
children from the French corpus are nearly identical to reported MLU norms of typically developing children in English (Brown 1973; Miller 1981).

Insert table 1 about here

Step $\mathbf{V}$ checked the accuracy of the software's identification of all potential F-LARSP structures from the master list. These checks compared the software's identification of target structures to those carried out by hand. An error rate of approximately $5 \%$ was determined, mainly resulting from the software's lack of structure selection.

Step VI honed the master list of structures down to the next version of the F-LARSP using descriptive statistics from the children's corpus along with the application of the first criterion of Bol and Kuiken (1987) which states that a minimum of $50 \%$ of the population at a given age must use the structure to be considered as the age of acquisition. This in turn allowed for the placement of each structure at an appropriate stage, using an age-based distribution of stages. Any structure that was never reached by at least $50 \%$ of the children of any age was omitted from the developing F-LARSP chart at this stage. It was later decided that a small number of structures not meeting this criterion would be included on the chart. An explanation of these exceptions is provided at the beginning of the discussion section.

As a second part of this final step, some small changes were made to the working chart. Except for a few key items, the chart has been limited to include only structures which the software can identify automatically. In addition, a small number of additional structures that do not meet the Bol and Kuiken requirements, but are potentially clinically relevant, have been added to the chart. These are clearly labelled on the final chart presented in Table 2 as each structure on the chart is accompanied by the percentage of children who produced the structure at a given stage. A usable F-LARSP chart and complete statistics about children's production of LARSP structures will be made available at the web site www.modyco.fr/flarsp/.

\section{Results}

Insert table 2 about here (F-LARSP Chart)

Insert table 3 about here (key to abbreviations used on F-LARSP Chart)

This chart represents the final result of the project. All structures appropriate to English and not French have been omitted and several new structures, relevant to French, such as the dislocations, have been added. This meets our first earlier-stated goal. Structures are divided into the four categories of "clause", "phrase", "word" and "other" with each being listed a single time, at the earliest age that over $50 \%$ of the children used the structure (apart from the few 
exceptional structures that never reach the $50 \%$ criterion). It is interesting to note the large number of morphosyntactic structures acquired by the age of 3 as this contrasts with the smaller number acquired from age 3;0-4;0. However, this final year shown on the chart represents important leaps in syntactic complexity based on coordination and subordination.

New software was developed and tested for accuracy in its ability to identify the structures of the F-LARSP 1.0 in comparison to identification by hand of trained experts. Results around 95\% accuracy were found to be acceptable considering that the software error tended towards non-identification of structures as opposed to overidentification of structures. This accurate usage of the software met our goals of designing a new morphosyntactic identifying software and verifying its accuracy.

The software, in turn, allowed us to carry out very simple descriptive statistics to determine during which age-range any given structure was produced by $50 \%$ or more of the children in that range. This allowed us to place all structures achieving $50 \%$ or more onto the chart in the appropriate range, thereby achieving our final goal.

The achievement of each of our five stated goals go a long ways towards satisfying the primary aim of creating the most useful LARSP adaptation possible for French-speaking clinicians. However, an additional decision was made to include a small number of structures on the FLARSP 1.0 that did not fit the strict criteria of 1) usage by $50 \%$ of the children at a given age and 2) the ability to be identified by the computer program. In our attempt to make the FLARSP as clinically relevant as possible, a small number of additions were made to the chart. The reasoning behind this final step of adding certain structures that did not meet Bol and Kuiken's criteria is discussed in the following discussion section.

\section{Discussion}

With results clearly displaying at what age-related stage particular structures become regular, it is relatively simple to assign chosen structures to the appropriate stage. However, a more difficult question to answer is the one that asks how many morphosyntactic structures need be included to provide the most valuable data for evaluating child language and particularly for noting indicators of language impairment. When a variety of options present themselves, it is better to include more or fewer structures on the completed F-LARSP chart? Regarding the number of items to be included, our analyses show that several structures, due to their rarity, never attain the level of $50 \%$. This leads to the question of whether these structures are relevant enough to be included on the new chart. By pertinent categories we mean categories that are frequent enough to be of normative use. Rarely used categories are less useful in helping to identify children with language difficulties because their low production by either a typically developing child or one with language impairment is likely to be the norm and therefore not 
especially informative. It is impossible to know whether children use these rarer targets by random chance, as fixed forms, or because they master them. On the contrary, frequent categories are more useful for diagnostic and remediation purposes. If they are common and appear in the production of at least $50 \%$ of children, they are likely to be found even in children with language disorders (or at least a large percentage of these categories should be found). This is an argument for omitting structures that never attain 50\%. This was the guideline followed in GRAMAT (Bol and Kuiken's Dutch adaptation of LARSP) where they kept only categories produced by at least $50 \%$ of the children. However, might the inclusion of rarer items on the FLARSP be of help to the clinician when planning treatment and when examining the progress of an individual patient? The Dutch version is greatly pared down from the English LARSP but could it be that this leads to a loss of valuable data? One reason to omit all structures that don't reach the 50\% threshold regards the time it has traditionally taken to complete a LARSP chart. This should mean that including fewer structures makes the administration of the LARSP quicker. However, as we have developed a program which makes analysing a transcript automatic in regard to finding F-LARSP structures, the time constraint becomes considerably less problematic although some clinicians may choose to carry out a hand check for very specific analyses. The automatic F-LARSP processing feature makes the pruning of all non frequent categories less necessary because infrequent categories do not make the evaluation process more time consuming. For this reason, it could be interesting to keep infrequent categories for the purpose of performing more fine grained evaluations of older children or children with unusual production patterns. Of course, categories that are not used at all tend to clutter the evaluation process so we have chosen a compromise. On the F-LARSP 1.0 we therefore decided to include items that never attain $50 \%$ but which have been used by a minimum of $30 \%$ of children at a certain stage as long as they are identifiable by the software.

With the major decisions made about which structures to include and at which stage to place each one, questions of form needed to be dealt with. The original LARSP has an elegant foundation where Stage 2 corresponds mainly to either two clause elements or two phrase elements together, Stage 3 corresponds mainly to three elements making up a unit, and a row of expansions connect the stages. However, our results now show what were Stage 2 clause elements in the original LARSP to be spread through Stages 2-4 in the French version or inversely old stage 3 and stage 4 are now placed in stage 1 or 2 . This redistribution of stages makes elements such as expansion lines that link stages seem inappropriate. We did however, include expansions not for the sake of bridging two stages, but in order to show the development of a clause element beyond the single word. The overall format of these sections have been changed though to accommodate the structures that can be identified automatically.

Furthermore, we find that the elements of the original English version LARSP's stage V which focus on the development of coordination and subordination to be problematic. The developed software is unable to successfully identify elements from Stage V and higher, yet information regarding a child's ability to form complex sentences is vital. For this reason, stage $\mathrm{V}$ of the chart is being kept in a nearly identical form to that of the original version and will for the time being need to be carried out by hand. Stages higher than $V$ have been omitted as they 
cannot be identified by the software and are arguably less informative than Stage V. Further work on developing software in this direction is planned.

Overall, the chart has in some ways changed greatly from the original. The English version of the chart has an elegance of numbered stages that match with the number of elements in each structure along with expansion lines which show movement from one stage to the next. This style has been lost in our decision to use age norms based on strict criteria and the analysis of a large corpus. What has been lost in one area though, is hopefully made up in the accuracy in mapping of the morphosyntactic structures to the appropriate age of French speakers. Another sizeable advantage is the automation of the process.

As indicated earlier, this version of the F-LARSP shown in this article is unlikely to be the only one. Future plans for the F-LARSP include using the tool in different settings and with a variety of groups including older children and those with language difficulties. We expect that this will provide invaluable feedback from a community of users. Versions using different criteria will then be developed and placed online to provide maximal access and to attempt to meet a variety of needs of different users. These will be accompanied by detailed instructions explaining the construction and use of the chart, how it can be carried out automatically if desired and how the information provided by the F-LARSP can be used in clinic.

\section{References}

Ball, M. J. (1988). LARSP to LLARSP. Designing a Welsh grammatical profile. Clinical Linguistics and Phonetics, 2, 55-73

Ball, M. J. (1999). Reynell Developmental Language Scales III: A quick and easy LARSP? International Journal of Language \& Communication Disorders, Vol.34(32),

Bol, G. W., \& Kuiken, F. (1990). Grammatical analysis of developmental language disorders: A study of the morphosyntax of children with specific language disorders, with hearing impairment and with Down's syndrome. Clinical Linguistics and Phonetics, 4, 77-86.

Brown, R. W. (1973). A first language: the early stages. Cambridge, Mass.: Harvard University Press.

Crystal, D., Fletcher, P., \& Garman, M. (1976). The grammatical analysis of language disability. London: Edward Arnold.

Dubois, J. (1965). La grammaire structurale du français. Paris : Larousse. 
Dumez, M. (2010). Analyse des conditions de passation et d'application du LARSP en vue de son adaptation francophone. Mémoire inédit présenté en vue de l'obtention du titre de master en logopédie, Université de Liège.

Gavin, W. J., Klee, T. \& Membrino, I. (1993). Differentiating specific language impairment from normal language development using grammatical analysis. Clinical Linguistics and Phonetics, 7, 3, 191-206.

Hickey, T. (1990). ILARSP: a grammatical profile of Irish. Clinical Linguistics and Phonetics, 4 (4), 363-376.

Joffe, B. S., Doyle, J. \& Penn, C. (1996). The persisting communicative difficulties of 'remediated' language-impaired children. International Journal of Language and Communication Disorders, 31, 4, 369-385.

Kail, M. (1989). Cue validity, cue cost, and processing types in sentence comprehension in French and Spanish. In B. MacWhinney \& E. Bates (Eds). The cross-linguistic study of sentence processing. Cambridge : Cambridge University Press, 77-117.

Lee, L. (1974). Developmental Sentence Analysis. Evanston, IL: Northwestern University Press.

Le Normand, M. T. (1986). A developmental exploration of language used to accompany symbolic play in young normal children (2-4-years-old). Child: Care, Health and Development, $12,121-134$.

Lowe, M., \& Costello, A. J. (1976). Manual for the Symbolic Play Yest, Experimental Edition. Windsor: NFER.

MacWhinney, B. (2000). The CHILDES project: Tools for analyzing talk (3rd) (2nd ed.). Hillsdale, N.J: Lawrence Erlbaum.

McCartney, E. (1993). Assessment of expressive language. in Beech, J. R., Harding, L. and Hilton Jones, D.. (Eds), Assessment in Speech and Language Therapy, 35-48.

Miller, J.F. (1981) 'Eliciting procedures for language' in Miller, J.F. (ed) Assessing Language Production in Children London: Edward Arnold.

Paradis, C. \& El Fenne, F. (1995). French verbal inflection revisited: constraints, repairs and floating consonants. Lingua, 95, 169-204.

Parisse, C. and Le Normand (2006). Une méthode pour évaluer la production du langage spontané chez l'enfant de 2 à 4 ans, Glossa, 97, 10-30.

Parisse, C., Maillart, C. and Tommerdahl, J. (in press) Editors (Ball, M., Crystal, D. and 
Fletcher, P. Assessing Grammar: The Language of LARSP.

Oetting, J. B., \& Hadley, P. A. (2009). Morphosyntax in Child Language Disorders. In R. G. Schwartz (Ed.), Handbook of child Language Disorders (pp. 341-364). New York: Psychology Press.

Samadi, H. \& Perkins, M. (1998) P-LARSP: A developmental language profile for Persian. Clinical Linguistics \& Phonetics, Vol. 12, No. 2 , Pages 83-103

Scarborough, H. S. (1990). Index of Productive Syntax. Applied Psycholinguistics, 11(1), 1-22.

Vial, C. (2010). Adaptation française du LARSP. Aspects linguistiques. Mémoire inédit présenté en vue de l'obtention du titre de master en logopédie, Université de Liège. 


\section{ACKNOWLEDGMENTS}

The authors thank Cécile Vial and Mélanie Dumez for the precious help for the collection and the transcription of the data about 18 and 21 month-old children. We also thank MarieThérèse Le Normand for allowing us to use her invaluable corpus of child language. 
Table 1 Production information of the corpus reporting the children's age, number of children per age group, mean number of utterances and mean length of utterances with standard deviation

\begin{tabular}{|l|l|l|l|l|l|l|l|l|l|l|l|}
\hline $\begin{array}{l}\text { Age in } \\
\text { months }\end{array}$ & 18 & 21 & 24 & 27 & 30 & 33 & 36 & 39 & 42 & 45 & 48 \\
\hline $\begin{array}{l}\# \text { of } \\
\text { children }\end{array}$ & 10 & 13 & 41 & 31 & 37 & 36 & 40 & 34 & 34 & 33 & 32 \\
\hline $\begin{array}{l}\text { Mean } \\
\text { utterances }\end{array}$ & 87 & 117 & 73 & 83 & 94 & 110 & 113 & 130 & 118 & 117 & 109 \\
\hline $\begin{array}{l}\text { Mean } \\
\text { length of } \\
\text { utterances }\end{array}$ & 1.3 & 1.5 & $\begin{array}{l}1.5 \\
(0.4)\end{array}$ & $\begin{array}{l}2.1 \\
(0.8)\end{array}$ & $\begin{array}{l}2.5 \\
(0.7)\end{array}$ & $\begin{array}{l}3.2 \\
(0.7)\end{array}$ & $\begin{array}{l}3.4 \\
(0.9)\end{array}$ & $\begin{array}{l}3.5 \\
(0.5)\end{array}$ & $\begin{array}{l}3.7 \\
(1.1)\end{array}$ & $\begin{array}{l}4.0 \\
(0.7)\end{array}$ & $\begin{array}{l}4.0 \\
(1.0)\end{array}$ \\
\hline
\end{tabular}


Table 2 The F-LARSP 1.0 Chart indicating morphosyntactic structures produced by children of specific age groups with percentages indicating the prevalence of children who used the structure at least one time in their spontaneous language sample

\begin{tabular}{|c|c|c|c|c|c|c|c|c|c|c|c|}
\hline \multirow[b]{2}{*}{ Stade $1(1 ; 6-2 ; 0)$} & \multicolumn{3}{|c|}{ Clause } & \multicolumn{4}{|c|}{ Phrase } & \multicolumn{2}{|c|}{ Word } & \multicolumn{2}{|l|}{ Other } \\
\hline & & & & $\begin{array}{l}\text { DN } \\
62 \% \\
\text { ProP } \\
69 \%\end{array}$ & $\begin{array}{c}\text { ProO } \\
70 \% \\
\text { NN } \\
30 \%\end{array}$ & & & $\begin{array}{r}\text { Aux } \\
54 \% \\
\text { Presen } \\
69 \%\end{array}$ & $\begin{array}{c}\text { PP } \\
62 \%\end{array}$ & $\begin{array}{c}\mathbf{Q} \\
85 \% \\
\text { Voc } \\
100 \%\end{array}$ & $\begin{array}{c}\text { Loc } \\
100 \%\end{array}$ \\
\hline Stade $2(2 ; 0-2 ; 6)$ & $\begin{array}{c}\text { AX } \\
81 \% \\
\text { Vo } \\
68 \%\end{array}$ & $\begin{array}{c}\text { SV } \\
90 \% \\
\text { SVA } \\
77 \%\end{array}$ & $\begin{array}{l}\text { VC } \\
76 \% \\
\end{array}$ & $\begin{array}{c}\text { AuxPP } \\
71 \% \\
\text { Cop } \\
78 \%\end{array}$ & $\begin{array}{c}\text { Modlnf } \\
52 \% \\
\text { NegV } \\
74 \%\end{array}$ & $\begin{array}{l}\text { PrN } \\
55 \% \\
\text { NegO } \\
58\end{array}$ & $\begin{array}{l}\text { ther } \\
\%\end{array}$ & $\begin{array}{l}\text { Inf } \\
87 \%\end{array}$ & $\begin{array}{l}\text { Mod } \\
68 \%\end{array}$ & $\begin{array}{l}\text { ExpA } \\
55 \% \\
\text { ExpV } \\
71 \%\end{array}$ & $\begin{array}{l}\text { ExpO } \\
58 \%\end{array}$ \\
\hline Stade $3(2 ; 6-3 ; 0)$ & $\begin{array}{c}\text { SVO } \\
81 \% \\
\text { Dislo-G } \\
68 \%\end{array}$ & $\begin{array}{c}\text { VCA } \\
53 \% \\
\text { Dislo-D } \\
83 \%\end{array}$ & $\begin{array}{l}\text { VOA } \\
39 \%\end{array}$ & $\begin{array}{c}\text { SO } \\
61 \% \\
\text { cX } \\
61 \% \\
\text { RelPro } \\
56 \%\end{array}$ & $\begin{array}{c}\text { NA } \\
61 \% \\
\text { PrDN } \\
94 \% \\
\text { PrDAdjN } \\
31 \%\end{array}$ & $\begin{array}{c}\text { Others } \\
64 \% \\
\text { ProPro } \\
69 \% \\
\end{array}$ & $\begin{array}{c}\text { DAdjN } \\
83 \% \\
\text { Conj } \\
83 \%\end{array}$ & & & $\begin{array}{l}\text { ExpS } \\
83 \%\end{array}$ & $\begin{array}{l}\text { ExpC } \\
53 \%\end{array}$ \\
\hline Stade $4(3 ; 0-3 ; 6)$ & $\begin{array}{l}\text { SVC } \\
53 \%\end{array}$ & $\begin{array}{c}\text { SVOA } \\
63 \%\end{array}$ & $\begin{array}{c}\mathbf{V V} \\
32 \%\end{array}$ & $\begin{array}{l}x C x \\
30 \%\end{array}$ & & & & & & & \\
\hline Stade $5(3 ; 6-4 ; 0)$ & $\begin{array}{r}\text { SVOC } \\
31 \% \\
\text { S O C A }\end{array}$ & $\begin{array}{l}\text { Coord } 1 \\
\text { Subord }\end{array}$ & $\begin{array}{ll}1+ \\
1+\end{array}$ & $\begin{array}{c}\mathbf{A}+\mathbf{A} \\
55 \%\end{array}$ & $\begin{array}{r}\text { PrNN or } \\
38\end{array}$ & PrAdjN & & & & & \\
\hline
\end{tabular}




\section{Table 3 Key to abbreviations used in the F-LARSP 1.0}

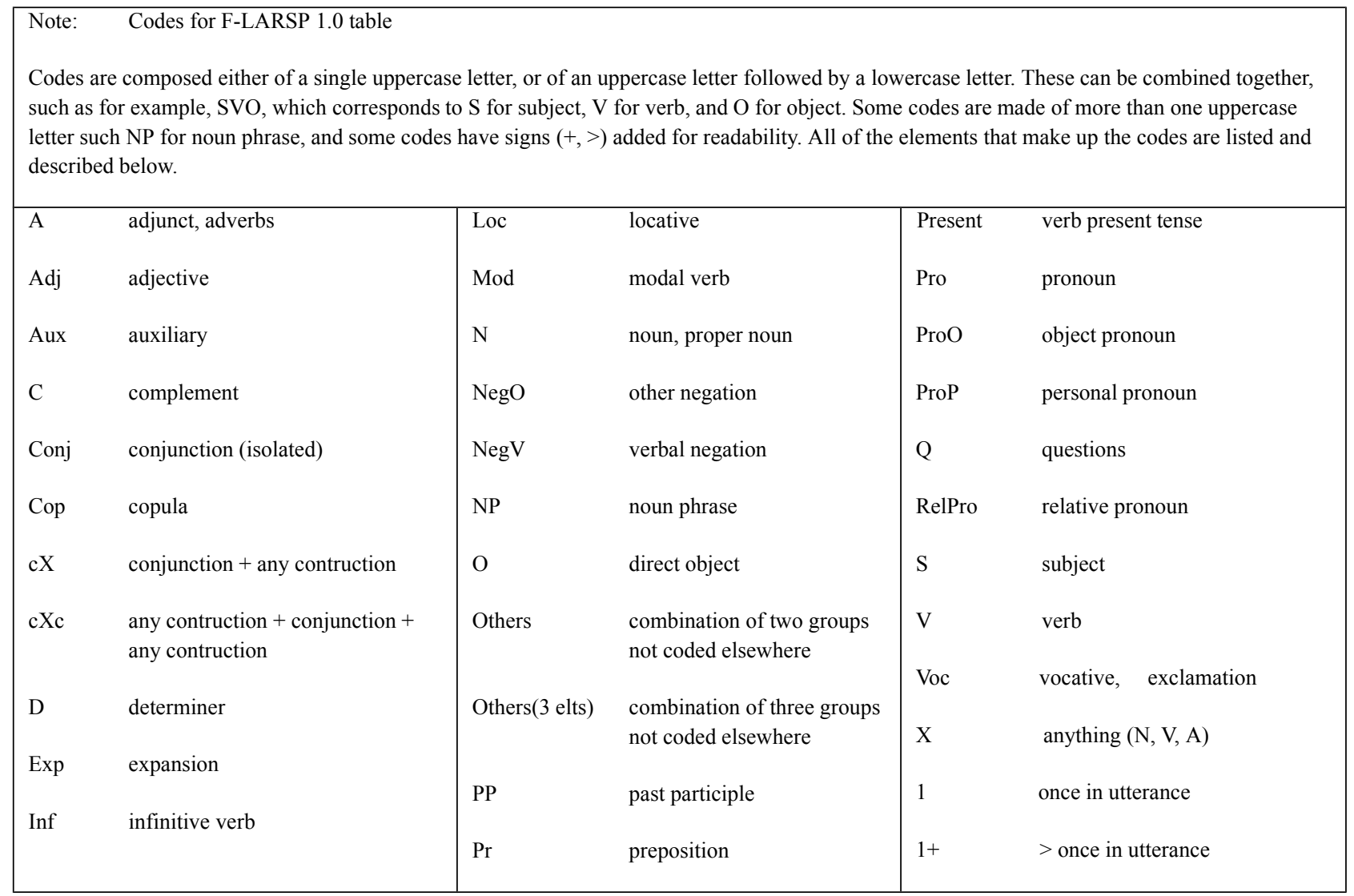

